The fact that the arms and hands were more or less involved is distinctly in favour of strychnine.

A point which was specially noticeable was that outside influences, noises, jars, movements of the bed, bright light, etc., had no effect whatsoever in causing or increasing the intensity of the spasms.

\section{Persistent Rigidity.}

The persistent rigidity and partial relaxation from time to time point strongly to a chronic variety of tetanus.

\section{Pain and Temperature.}

The absence of all acute pain, even during the severe exacerbations of the spasms, seems to be quite an unusual feature.

A high temperature used to be thought diagnostic of tetanus, but more recent researches have shown that strychnine poisoning gives rise to high temperatures as well. In both diseases the temperature is apt to rise in a marked degree after death. The presence of this postmortem rise was not ascertained here.

\section{Rigor Mortis.}

In strychnine poisoning the back especially is generally rigid for a long time after death, and in a certain famous case it was found to be so two months after. It has, however, been known to pass off after twenty-four hours. It is usually present very shortly after death.

On the whole the balance of evidence seems to be slightly in favour of a chronic form of tetanus. The case was a remarkable one, for the balance between the two conditions, especially when she was first seen, was so evenly adjusted that each slight alteration in her symptoms seemed to incline it first in one direction and then in the other.

As time went on it became increasingly difficult to entertain the idea that the case was one of strychnine poisoning, especially when one considered that the duration of such a case from the onset of the symptoms averages two hours.

But even supposing that the spasms were due to a chronic form of tetanus, many of the symptoms still remain to be accounted for in some other way.

I am indebted to Dr. Francis Hawkins, under whose care the patient was in this hospital, for the permission to publish these notes.

\section{PRELIMINARY NOTE ON THE HISTOLOGY OF EGYPTIAN MUMMIES.}

\section{By MARC ARMAND RUFFER, M.D.,} ALEXANDRIA.

Some time ago my friend Professor Elliot Smith, F.R.S., gave me some fragments of mummies of the XXI dynasty (dating from 1000-1050 в.c.), and I endeavoured to examine these fragments by histological methods. As far as I knew then, this was practically the first attempt to study microscopically the minute structure of tissues mummified for about three thousand years; at any rate, I found nothing bearing on this subject in the literature at my disposal, but I was informed that Professor Looss of Cairo had shown the striation of mummified muscular fibres to his colleagues. I demonstrated some of my sections at the Sheffield meeting of the British Medical Association and at the December meeting (1908) of the Cairo Scientific Club. Quite lately my friend Mr. Shattock has read a paper on a similar subject before the Royal Society of Medicine.

\section{METHOD.}

It was found impossible to obtain good microscopical sections without first restoring, to some extent at any rate, their flexibility to the tissues, as their brittleness and hardness broke the edge of the microtome knives; even when a fair section was obtained, this invariably crumbled up when transferred to the slide. I need not describe the various methods tried and rejected, but it will be sufficient to note that, by combining an alkaline salt such as carbonate of soda with a hardening reagent such as alcohol or formol, the mummified tissue placed in the mixture gradually swells up and resumes its former shape.
The solution which has given me the best results is composed of alcohol 100 parts, water 150 parts, 5 per cent. carbonate of soda solution 60 parts. In many cases, how: ever, such a solution softens the tissues too much, and more alcohol must then be added.

After a period of time, the length of which depends on the bulk and nature of the tissue, the solution is replaced by 30 per cent. alcohol, and more alcohol is added day by day. After two or three days the softened tissue is trans. ferred to absolute alcohol, then chloroform, paraffin, and cut secundum artem. During these manipulations the tissue remains pliable, though it shrinks a good deal. Very thin sections do not present any particular advan. tages, and I generally use three divisions of Minot's microtome. Such preparations stain readily with the ordinary dyes, but for tissues such as muscular fibre teased preparations, after maceration in 1 in 10,000 caustic potash, give excellent pictures.

\section{Results.}

I have prepared sections of muscle (voluntary, cardiac, and involuntary), blood vessels, skin, intestine, stomach, liver, kidney, bone, mammary glands and testicles, and the main characters of all these organs and tissues can be readily recognized. The striation of muscular fibre, for instance, the muscular coats, the submucous tissue, and occasionally even the glands of the intestines and the convoluted tubules, the straight tubules and glumeruli of the kidneys, the various layers of the skin can be identified with certainty. I have no.doubt that coarse pathological changes, such as inflammation, cirrhosis, tubercle, or cancer, could be demonstrated by this method.

\section{fftemurama:}

\section{MEDICAL, SURGICAL, OBSTETRICAL.}

\section{NUTMEG POISONING.}

NutMeg poisoning itself is rare, and this case is especially interesting in that, although the, amount taken was so small, it led to very definite symptoms and also to my hearing of two similar cases. I was sent for to see a man, aged 22 , who had suddenly been taken ill after a midday meal of cold mutton and milk pudding. The pudding was a small one and he had eaten the whole of it himself. It was flavoured with about a quarter of a moderately-sized nutmeg. Within a few minutes he felt his face flush and he began to itch, all over and went up to his bedroom. Here he was immediately sick and vomited his dinner, and at the same time his nose began to bleed. He then lay down on his bed and did not remember anything more till I roused him. I saw him about half an hour later. He was lying face downwards on the bed in a completely collapsed condition. His face was swollen, especially his lips and lower eyelids, and he was cold and markedly cyanosed. The pupils were contracted, bat not pin-point. The radial pulse was rapid and scarcely palpable; the heart was thumping and irregular. On speaking to him he appeared dazed, but was able to give me a clear description of what had happened. His tongue was clean, slightly swollen, and he complained of a feeling of fullness in his throat. He also had some slight abdomiral pain, but this soon passed off. About an hour later the cyanosis had disappeared and was replaced by a diffuse flush. His face was still swollen, and he still complained of slight itching. The pupils were now normal. There was no further vomiting, and beyond a feeling of drowsiness there were no further symptoms, and he awoke the next morning feeling perfectly well. The vomit obviously consisted of his dinner in an undigested condition. It did not smell of nutmeg. Careful inquiry elicited no other cause for what was evidently a case of acute poisoning. The patient was a healthy, well-developed youth.

The two other cases were described to me by his mother, a publican's wife. Some years ago two barmaids in her employ were awakened at night with abdominal pains, vomiting, and diarrhoea. Their faces were noticed to be swollen and blue. On going to bed they had each taken half a nutmeg in a glass of stout, as they had been assured that this would cure a rash they had. They recovered without further symptoms.

Holmdale, Parkstone.

K. Mayon Gibbins. 